\title{
Application of National Opera Singing Techniques on Vocal Music
}

\author{
Jing $\mathrm{Li}^{1, \mathrm{a}}$ \\ ${ }^{1}$ Anyang Vocational and Technical College, Anyang, Henan, 455000 \\ a email
}

Keywords: National Vocal Music; Traditional Opera; Singing Skills; "Mei Lanfang"

\begin{abstract}
In recent years, the traditional opera singing skills in Chinese folk song singing is research subject of common concern. Taking songs "Mei Lanfang" for example, the work in the multi-dimensional analysis of Humanistic interpretation and creation techniques, in order to witness the personal experience to explain the singing process understanding and interpretation, in the grasp of national vocal music and traditional Chinese opera singing commonness and individuality, based on the "Tunes" and "performance" and other aspects of a more intensive focus on exploration.
\end{abstract}

\section{Introduction}

Chinese traditional opera rooted in the soil of Chinese traditional culture, after a long period of accumulation and improvement, forming a distinctive, rich in content and theoretical system has an independent discipline certain scale. National Vocal Music in Chinese traditional opera, folk and other art forms under nourishment, and learn from the West into the theoretical system and related techniques Concerts An evolving art form of singing. The former is the root, the latter leaves, deeply rooted. In recent years, both in the course of independent development, learn from each other, learn from fusion, complement each other, and attach great importance to national vocal music circles. Many national vocal music experts and scholars from different angles and sides in this area conducted in-depth exploration and research, we have made encouraging progress. A large number of relevant literature not only made the basis of practice in this area is enhanced, and achieved fruitful results. White Ning from different sides of history, culture and music of Chinese Modern National Vocal Music from the historical heritage, evolution process, the determining factor, forming conditions and other aspects of a more comprehensive analysis. Cao Yuping of traditional opera artistic value and significance in the development of national vocal music made a profound exploration. Wang Baorong proposed opera musical elements, characteristics, skills in national vocal music creation value and meaning, and so on.

Throughout the more theoretical literature, mainly deals with the formation of national vocal music, traditional opera in National Vocal formation role, to the traditional opera singing some of the techniques used, and drama arts play in developing nations throughout the vocal the important role of other issues. But Chinese opera after hundreds of years of development, the formation of all-inclusive and highly personalized art treasure. Its manifestations, there is action type, style of singing has been argued, drums have been, there are sets of martial arts no matter what aspect are worth exploring research National Vocal valuable asset. However, studies of national vocal music and opera art inheritance, reference, the relationship between the use of, in particular, "sing, read, do," and other aspects of national vocal music is closely related to detailed in-depth exploration of the current research is still slightly less. This paper tries to run the chamber opera art, "sing, read" performance "to do" to start, to the creation of the song "Mei Lanfang" for example, combining aspects of traditional opera singing Runqiang and performances of traditional opera singing Reference the value of national vocal music art drama draw for concrete analysis. Serve as a catalyst to arouse deeper inquiry.

\section{The Innovation Needs of Chinese National Vocal Music Development}

Chinese national vocal music through the continuous exploration of several generations of outstanding singers and vocal music educator, has formed the corresponding aesthetic principles 
and unique form of singing, made a lot of singing and theoretical results. National vocal singing, skills, characteristics, ethnic vocal music experts, educators explore the long-term have a different meaning; from the 20th century and 1950s, "foreign soil dispute", to singing in the 1980s, the theory of technology shape. September 1983, China Musicians Association Guangdong Branch of National Music Committee, folk music labs in Guangdong Province jointly organized the "National Vocal Music Research Symposium." For singing the national characteristics proposed preliminary definition: national singing mainly reflected in the "word, chambers, sound, feeling, taste," five words "especially after the 1990s, with the extensive exchanges and foreign vocal art. National vocal majors artistic vision than before to broaden the vocal ability and grasp of contemporary general has been greatly improved. into the 21st century, the famous vocal educator Professor Jin Tielin academic "2005 China National vocal Music Forum" report, the definition of national vocal music presented another new innovation, the definition of national vocal summarized as seven words:. "sound, emotion, character, taste, table, support, like" third national vocal Music in 2008 at the seminar, Professor Jin Tielin the modern national vocal music orientation in "Science, ethnic, artistic and times."

From the above it several forums and seminars of national vocal music is not difficult to see that China National Vocal Music in the long-term development is improving, explore and perfection. And can affirm its "sound, word, taste, feeling" the development of national vocal music has always been the same soul. Both in vocal technique, singing form, creative practice, theory construction, professional education, artistic style have achieved fruitful results. But it does not mean "perfect." Since the 1920s, due to the influence of Western culture brought about by the Western Concerts input techniques, Western music and Western aesthetic values of the theoretical system of China, resulting in the development of Chinese national vocal music some emphasis on "Western tendency". Teaching Mode in China specializing in music schools, from composition, orchestration, bel canto, vocalization national vocal music lessons and even concert works, etc., mostly follow the system and techniques of Western music. Now the era of national vocal music "new generation" singer a common problem: the national characteristics of style and color performance was still weak, especially for the lack of certainty on the singing style of "flavor" and personality. Appearance of the image presented to the audience is: different people singing the same song, almost taste; sing a different song, which sounds very few differences in the sound. In today's world environment multicultural exchange, the National Development and vocal music to the world, not just learn from Western singing techniques, but rather should be rooted in the soil of the national art of traditional culture, tradition, traditional learning, drawing on tradition Research on the basis of traditional, self-development. The essence of traditional national art, especially the art integrated feature traditional opera diversity of color, style, charm, performances, applied to the National Vocal Music, and thus the development of national vocal music has played an important supporting role.

\section{Learn From Each Other and the Need to Use the Path}

In various fields of culture, science, arts, learn from each other is essential. Musically, the previously mentioned, the National Vocal Music in vocal technique, vocal technique borrows heavily from Western methods, learn from Western composition techniques in the creation of instances are not uncommon. Similarly, the introduction of Western music is also folk music material. Such as the famous Italian opera composer Giacomo Puccini - "Turandot", the direct use of Chinese folk song "Jasmine" melody, which is a reference. Inherit and learn from, the older generation of singers in traditional Chinese vocal music, opera aspects of learning and inheritance, have a very strong foundation. Such as the famous singer Guo Lanying older 8-year-old began to learn Shanxi Road clapper, and later played the new national opera, she put the essence of the traditional art of opera songs into the play, so that lane is due to play, a firmer foundation, beautiful singing, action Xian training a generation of artists. In her dictation "from Shanxi clapper see traditional Chinese singing" a paper had made it clear from an early age to learn the art of opera solid foundation of her later in the national opera "White-Haired Girl" in the play "Xi'er" can be handy the biggest factor. Famous singer Li Gu Yi is also a small study Huagu origin, favored by the 
majority of the people Peng Liyuan Guo Lanying had studied drama teacher learning in Chinese national vocal music singers, from opera line of business are numerous, they are full of ethnic flavor and full of personality concert it is rooted in the style of traditional Chinese opera, and benefit from the concert, performing in one of the formation, which is the result of the exploration and the pursuit of the national vocal Music. Modern National Vocal Music in the concept of "traditional" somewhat forgotten and alienated, so that ethnic vocal training and singing there are shortcomings, especially in the singing style and strong work, the lack of national vocal music tradition of aesthetic education and traditional vocal techniques skills such singers sing works taste one thousand examples, how to make the singer on the concert works of different styles prominent personality and style, in the "foreign", "past serve the present" in the precise positioning? I carefully reviewed from 1981 to 2010, the beginning of a first period of nearly 30 years, "Chinese music" all journal articles. With regard to traditional opera singing skills Folk Music inherit each other, learn from a total of only 10 articles. More to learn how to refer to the traditional articulation articulation of literature, less substantive reach of the National Vocal traditional opera singing skills inherited, reference study. Through study and observation, I will play witnessed sang the song "Mei Lanfang," for example, from work to analyze how to learn from traditional opera Runqiang, articulation articulation, performances and other techniques in the actual use of the works as the starting point, and He studied traditional opera combined with the author after learning national vocal personal experience, try to learn from the use of traditional opera singing skills and national vocal singing style was a combination of specific research.

\section{The Case: the Song of "Mei Lanfang" Analysis}

The song "Mei Lanfang" is the Grand Prix of 2006 CCTV young singer launched a full-bodied style drama works, but also affect the industry in recent years, one of the larger national vocal music, a theme is unique, distinctive creations, the song to celebrate the Beijing opera artist Mei Lanfang motivation for the creation, elaborated Mei Lanfang their character and artistic style. Especially traditional opera elements in the works clever implantation, it has a high cultural character, affecting more widely.

One of Reference and Application on songwriting, lyrics. Guangzhou Daily in an interview with the author's words, he expressed these lyrics creative intent. Liupeng Chun said: "As a generation of artists Mr. Mei, who has his patriotic love Township, dedicated, refined, innovation, creativity, spirit, and Mei is a fellow, and people with opera, feel many things to say to the master . "so, as with fellow Liupeng Chun Mei Lanfang, with admiration of the heart, it should be about the creation of the lyrics.

It is a daughter of the moon, such as water, derived from the man of staunch Firelight. Thousands of style rolled into one, tender and soft are all efforts robbery. Chong fair half, half Su, span road from seeking self-charge. (2) packed up her daughter flexilis aromatic leaves, hold on man of integrity fresh bamboo. Xu Ran fluttering heart care, tender and soft, why not do the trail. Half the King of Chu, half Concubine, like Wu Zhuima soul weep tears Tears of Blood. (3) May also wish to snow, blue may also wish to snow. Some fragrant leaning cliffs, peak floating banner for hunting. Mei also iron, iron blue also. A loyalty burning flames, leaving the country to see the battlements. Opera, folk, song lyrics, lyrics of their sentence is diverse, but basically two categories: First, supposing symmetrical seven words, ten words, "vulgar talk stylistic change" or as "praise poem line"; Second, It is Long Short sentence tunes body (also seven words stretch of the Pan-sound or by word) or called a "song Department." Where more is seven words, ten words, the song "Mei Lanfang," the songwriter follows the traditional creative mode up and down the length of sentence structure text word written. Songwriter Wu Xiaoping said: "I had such a proposition is prohibitive, because Mr. Mei Lanfang is the generation of national opera master, if only to show him a song, and then concentrated ink can not just observe its detailed .2004 is the 110th anniversary of the birth of Mr. Mei Lanfang, Mei's hometown of Taizhou Municipal publicity Department, Mr. Ji Nianmei invited me to write a little work, I am trying to come up again and again still could not put pen to paper. Coincidentally, Liu Pengchun teacher just write a word called "Mei Lanfang", when he hit 
To tell me when I was really excited when you see the word draft of Liu's, the heart is more excited. What a word Oh! I think I must write, but also hard to write, write. After much thought, I decided to take the Western music and Chinese opera combining the road, so I came inspiration, borrowing elements of traditional Chinese opera refilling Mei masterpiece "The Drunken Beauty" in tone, a chant three sigh, twists and turns The last one go. "Song" Mei Lanfang "songwriter adopted Western music writing skills and a combination of Chinese opera, especially the first two draws on traditional opera opera" Drunken Beauty "Anti two yellow tone of [Siping tune] creative music . "[Siping tune] which is characterized by small plate, with stiff, and few with a board three, singing as supposing structure, stiffened plate off the end of the sentence sound re, the following sentence from the board eye off the junction tone do "(see the original spectrum of cases opera" Drunken Beauty "Yang Yuhuan aria" island Moon First turn Tang "). Application of the third paragraph of tight play traditional opera singing slow way. from a structural point of view, is a rubato intro, seventh subsection after entering the Adagio, after the first inter-Sec into the speed of play, and then immediately enter the Allegro last section down dozens entered Adagio rubato to end. as in the first phrase of its music section five sections, six bars, four bars, nine sections ranging from belonging to a non-isometric structure of the music, the use of traditional opera scattered, slow, medium, fast, loose way from tonality speaking, belong to the B-flat systems Palace Palace F tonal system switched alternately, entered the libretto of five sections belong to B-flat house, from the beginning of the interlude is converted to the $\mathrm{F}$ palace, the whole song has been falling between $\mathrm{B}$ and F Palace Palace kept alternately switching is performed. from the above analysis it is not difficult to see that music, whether it is music songwriter material, to the rhythm of tuning are all draw on traditional opera creative approach use them. of course, the whole song later orchestration, song writer also draws on Western composer orchestration techniques.

"Mei Lanfang" This is the first vocal music is praised Mr. Mei Lanfang's life the main line. As a singer first generation of Peking Opera master Mei Lanfang portrayed in life have a more comprehensive understanding, just as in traditional opera character analysis, in order to accurately locate the same role in place to grasp the character and interpretation work. To be able to identify the characters tone, the author of the song at the beginning of this study, we read the memoirs Mei "stage four decades of life" and "Xu Lan Yuan Caoqin life." "Stage four decades of life" is the Peking Opera master Mei Lanfang's life memoirs, art-based, supplemented account of life with the master's life work, a

"Xu Lan Yuan Caoqin life" is a famous Peking Opera musician Mr. Xu Mei Lan Yuan introduced in cooperation with the bits and pieces of a book 28 years from another angle to Peking Opera Mei from art for art innovation, rigorous, nation, country, family, friends, love, etc., made a further presentation and evidence. Later, I also watched the movie "Mei Lanfang" from different angles on the great master were more comprehensive understanding, to establish the characters sing songs in the image with a specific image positioning and grasp. "That's a daughter of the moon, such as water, derived from man's staunch Firelight," which is a description of two main lyrics of Peking Opera Mei quest, hardships and tireless. Such as "water moon" usually used to describe a woman, while on the stage Mei shaped by a variety of women's image than women woman, a woman on the stage like water is actually a staunch man shape, and to achieve such a high artistic level, and his art is the arduous inseparable. From the analysis of the meaning of "The Long Road from seeking self-charging" This sentence tells the Peking Opera Mei road pursuit, it seems he reprized the character Su, as for their own ideals without flinching, never give up. The second verse, the author describes what is Mei my noble character and his patriotism. Lyrics wrote: packed up her daughter flexilis aromatic leaves, hold on man's staunch fresh bamboo, "which is a description of two main categorically beard Ming Mei Lanfang during the war, not a national enemy performances, performance Art Howe generation indomitable strong backbone. "Xu Ran fluttering heart care," One implication is that he was bearded scene. third paragraph lyrics mainly praised Mei Lanfang, mainly praise for his art full contribution as "lean period fragrant cliffs, peak floating banner for hunting," he praised Beijing opera pilot role, and the last two lyrics, "the flames of a burning loyalty to stay with the country to see the battlements" it praises plum although falling aryl still in 
perpetuating the spirit of as word writers described him to a generation of Peking opera master of patriotism and love of the rural, dedicated, refined, innovation, creativity, spirit and truth all into the song among the lyrics.

With the above general understanding of the following works as a singer first thought is how to interpret this singing technique with special styles. First think of what kinds of sounds to interpret the most appropriate this piece, is the use of traditional opera singing (opera) singing to sing it or by national vocal singing style to sing opera actor duet requires this jargon??: "sing to a line, not a blockbuster. long if a line tone is clear, sharp, steady, well, otherwise it would noisy, chaotic, scattered, light." according to traditional Chinese opera vocal singing to sing the words, sounds will some flat, shallow, narrow, the volume is not too large, the sound would carry too far, especially in the latter part of the climax will heighten up. If exactly the way folk song singing concert, it will reach the sweet, strong, bright colors on a wide sound, but lacks charm drama. In the "Mei Lanfang" This is the first national vocal works, I believe that the use of traditional opera singing skills draw the Tunes for Folk Music and performing vocal technique combining the most appropriate interpretation.

\section{Conclusion}

Chinese traditional opera ancestors is inherited wealth, which bears an inexhaustible supply of nutrients, infiltration nourish generation after generation of people, regardless of Chinese opera can flourish with any kind of art world from singing, performances and other artistic achievements, Chinese national vocal music really wants to stand in the forest of world culture and art, learn, absorb and learn the essence of traditional Chinese opera will be the only way. Indeed, traditional opera to learn from and use does not mean fusion of rapid development is inseparable from the art to the brothers and sisters of the National Vocal Music Opera, the National Vocal Music interoperability between long. Into the traditional opera singing skills at the National Acoustic Music, it has been in recent years is one of the disciplines within the research topic of common concern. Experts and scholars in succession, drawing, using field research has achieved fruitful results. Later required on the further development of national vocal music, to inherit the essence of Chinese traditional culture in the art of opera, vocal music for the future of the nation to contribute, doing my duty, to pay greater hardships and efforts.

\section{References}

[1] Bai Ning. On the Development of Modern Chinese Vocal Music [J]. Symphony, 2004 (1): 88-93

[2] Cao Yuping. Value of Theatrical Art in National Vocal Music positioning [J]. Anhui Institute of Education, 2005 (1): 122-123.

[3] Wang Fei. On Chinese traditional opera singing skills in the use of National Vocal Music [J]. Hubei Radio and TV University, 2008 (8): 77-78.

[4] Wang Baorong. On the use of traditional opera in National Vocal Music in Contemporary Creation [J]. CONSERVATORY OF MUSIC, 2010 (3).

[5] Li Yu. Chinese classical opera on the integration of the seven "Occasional Enjoyment" [D]. Chinese Opera Research Institute, 1959.

[6] Xu Lanyuan (oral). Don documenting. Xu Lan Yuan Caoqin Life (Part III) [M]. Beijing: China Drama Press, 1963. 